\title{
Risk Factors for Metachronous Recurrence after Endoscopic Submucosal Dissection of a Gastric Neoplasm
}

\author{
A Reum Choe, Ki-Nam Shim, Tae Oh Kim, Sang Yoon Kim, Jiyoung Lim, Chung Hyun Tae, Chang Mo Moon, Seong-Eun Kim, \\ Hye-Kyung Jung, Sung-Ae Jung \\ Department of Internal Medicine, Ewha Medical Research Institute, Ewha Womans University College of Medicine, Seoul, Korea
}

\begin{abstract}
Background/Aims: Although endoscopic submucosal dissection (ESD) is an accepted treatment method for gastric neoplasm worldwide, metachronous recurrence often occurs. Here, we evaluated the risk factors for metachronous recurrence after ESD of gastric dysplasia or adenocarcinoma and also examined the effects of Helicobacter pylori (H. pylori) eradication.

Materials and Methods: Among 400 patients who underwent endoscopic resection from February 2005 to December 2014 at Ewha Womans University Hospital, the medical records of 180 patients were retrospectively reviewed.

Results: The enrolled patients included 118 men and 62 women, and their median age was $61.7 \pm 10.3$ years. During a median follow-up period of 34.5 months, metachronous recurrence occurred in $21(11.7 \%)$ patients. Multivariate analyses revealed that $H$. $p y-$ lori eradication did not have any preventive effects on metachronous recurrence. A family history of gastric cancer was the only risk factor for metachronous recurrence after ESD of the gastric neoplasm.

Conclusions: Metachronous recurrence was found to be related to family history of gastric cancer. However, $H$. pylori eradication had no preventive effects on metachronous recurrence after ESD of a gastric neoplasm. Therefore, intensive surveillance is required for patients who undergo ESD of a gastric neoplasm and have a family history of gastric cancer. (Korean J Helicobacter Up Gastrointest Res 2019;19:184-192)
\end{abstract}

Key Words: Endoscopic submucosal dissection; Metachronous recurrence; Stomach neoplasms

\section{INTRODUCTION}

Gastric cancer is the second most common malignant tumor and the third leading cause of cancer mortality in Korea. ${ }^{1}$ Recently, the detection rate of early gastric cancer (EGC) has significantly increased owing to advances in endoscopic technology and regular cancer screening program. 2,3 EGC is a gastric cancer that invades no deeper than the submucosa, regardless of lymph node metastasis. ${ }^{4}$ Currently, endoscopic submucosal dissection (ESD) has become the main treatment strategy for EGC resection and provides safer and curative outcomes. ${ }^{5-7}$

The general indications for ESD are the presence of a mucosal tumor, measuring $<20 \mathrm{~mm}$ in diameter and having differentiated histology but lacking both ulceration and visible lymphovascular invasion. ${ }^{8}$ A previous study revealed that long-term clinical outcomes such as local re-

Received: April 17, 2019 Revised: June 17, 2019 Accepted: June 19, 2019

Corresponding author: Ki-Nam Shim

Department of Internal Medicine, Ewha Medical Research Institute, Ewha Womans University College of Medicine, 260 Gonghang-daero, Gangseo-gu, Seoul 07804, Korea Tel: +82-2-6986-3122, Fax: +82-2-2655-2076, E-mail: shimkn@ewha.ac.kr currence, metachronous recurrence, overall survival rate, disease-free survival, and adverse events after ESD were comparable to those after surgical treatment of EGC, including the expanded indications. ${ }^{9,10}$ ESD was superior than surgical resection in terms of higher quality of life, minimal invasiveness, organ preservation, and shorter hospital stay. ${ }^{11}$ However, stomach preservation can increase the risk of local and metachronous recurrence, which means that these patients will need to undergo surgical or endoscopic resection (ER). ${ }^{12}$ According to the literature, the incidence of metachronous recurrence over a long-term period after ESD was reportedly 6.1\%, whereas that after partial gastrectomy was approximately $0.7 \%{ }^{13}$ It is critical to explain the potential risk factors for metachronous recurrence in patients who undergo ESD.

Although methods used to analyze risk factors for metachronous recurrence vary among studies, older age, multiple initial EGCs, family history of gastric cancer, and persistent Helicobacter pylori (H. pylori) infection are considered as common risk factors. Several studies have

Copyright $\odot 2019$ Korean College of Helicobacter and Upper Gastrointestinal Research

@ The Korean Journal of Helicobacter and Upper Gastrointestinal Research is an Open-Access Journal. All articles are distributed under the terms of the Creative Commons Attribution Non-Commercial License (http:// creativecommons.org/licenses/by-nc/4.0) which permits unrestricted non-commercial use, distribution, and reproduction in any medium, provided the original work is properly cited. 
focused on $H$. pylori infection as a modifiable risk factor for metachronous recurrence. However, whether the eradication of $H$. pylori could prevent metachronous recurrence after ESD of gastric neoplasm still remains controversial. $^{14}$ The aim of this study was to analyze the risk factors for metachronous recurrence among patients who underwent ESD for gastric neoplasm as well as to investigate the preventive effects of $H$. pylori eradication on metachronous recurrence among these patients.

\section{MATERIALS AND METHODS}

\section{Patients and study design}

We retrospectively reviewed the medical records from February 2005 to December 2014. A total of 400 patients diagnosed with gastric neoplasm who underwent ER were enrolled at Ewha Womans University Medical Center, Seoul, Korea. The primary and metachronous lesion of gastric neoplasm included dysplasia and carcinoma. We excluded 79 patients who underwent endoscopic mucosal resection, 81 patients who were followed up for $<1$ year, 33 patients who had a pathology other than that of adenoma and EGC, 26 patients who were not examined for H. pylori infection, and one patient whose tissue sample was missing. Therefore, a total of 180 patients participated in this study (Fig. 1). Clinical pathological variables, such as age, sex, smoking status, tumor location (upper: cardia and fundus, middle: body and angle, and lower: antrum and prepylorus), endoscopic gross appearance (elevated, flat, and depressed), tumor size, histological examination results, invasion depth, $H$. pylori infection status, follow-up duration, and family history of gastric cancer among first-degree relatives were determined based on medical records. The study was allowed by the Ethics Committee of the Ewha Medical Research Institute (IRB number: 2019-02-006) and was implemented in compliance with the Declaration of Helsinki.

\section{Detection of $H$. pylori infection and its eradication}

Infection with $H$. pylori was regarded as positive when at least one positive result was obtained in urease breath test $\left(\right.$ Otsuka ${ }^{\circledR}$, Tokyo, Japan), rapid urease test $\left(\right.$ ClOtest $^{\circledR}$; Delta West, Bentley, Australia), or histologic assessment (modified Giemsa staining) conducted using gastric biopsies from the antrum and greater curvature of the body. H. pylori eradication therapy was performed based on Korean guidelines for $H$. pylori infection. ${ }^{15}$ The first-line treatment included 1,000 mg amoxicillin, $500 \mathrm{mg}$ clarithromycin, and a standard dose of proton-pump inhibitor (PPI) taken twice a day for a week. If this treatment failed, a second-line regimen was prescribed for a week. This regimen comprised four drugs: $250 \mathrm{mg}$ metronidazole (three times a day), $500 \mathrm{mg}$ tetracycline (four times a day), $240 \mathrm{mg}$ bismuth (four times a day), and a standard dose of PPI (twice a day). Either the urease breath test,

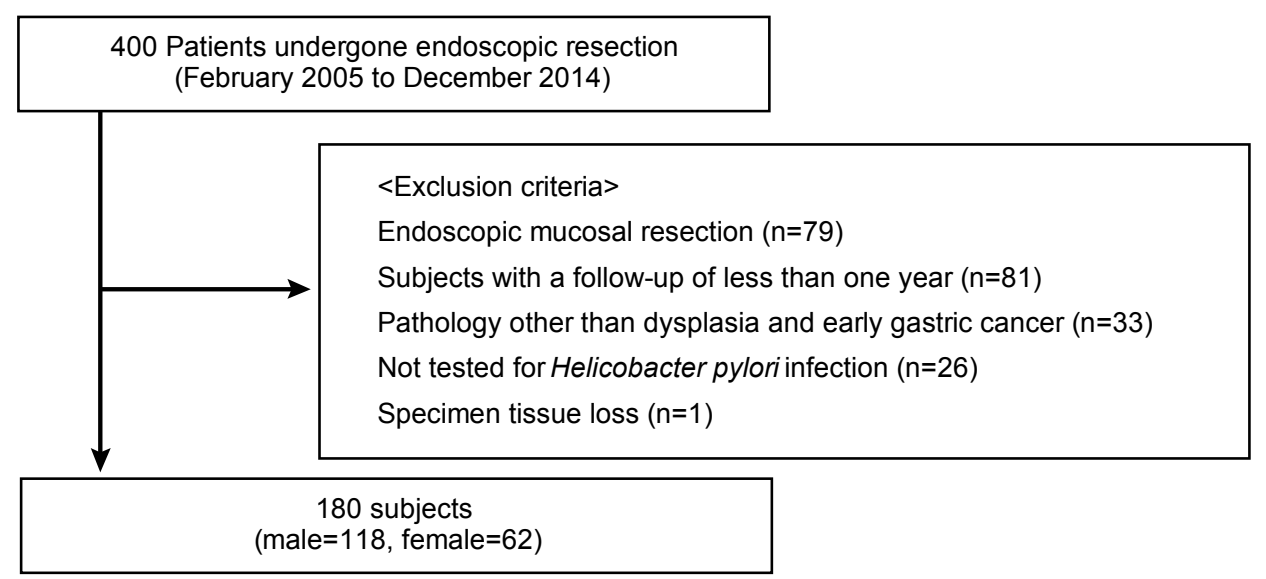

Fig. 1. A flow diagram of the patient selection method in this study. 
rapid urease test, or Wright-Giemsa staining of gastric biopsy samples was performed to confirm successful $H . p y^{-}$ lori eradication.

\section{Definition of metachronous recurrence}

The diagnostic criteria for metachronous recurrence proposed by Warren ${ }^{16}$ were used to categorize synchronous and metachronous tumors. Generally, metachronous gastric tumor is defined as gastric tumor located distant from the original tumor over a 1-year period after ER. Gastric tumor detected within 1 year after ER should be regarded as a previously missed synchronous gastric tumor.

\section{Endoscopic submucosal dissection technique and follow-up}

All ESD procedures were performed by two expert endoscopists (KNS, HKJ) by employing an insulated-tip knife (KD-611L; Olympus Medical, Tokyo, Japan) or Dual knife (KD-650; Olympus Medical). After the lesion was examined, argon plasma coagulation was performed in which a perimeter of $5 \mathrm{~mm}$ enclosing the lesion with several spots was marked using the tip of a probe. Normal saline mixed with indigo carmine and diluted epinephrine $(1: 100,000)$ was injected to lift the mucosal layer. A circumferential mucosal incision was performed outside the marking dots. The submocosa connective tissue was dissected using electrosurgical knife. This procedure is concluded on achievement of hemostasis. Follow-up endoscopic examination was scheduled at 3, 6, and 12 months post-ESD as well as on an annual basis subsequently to evaluate the completeness of resection and to detect metachronous recurrence. Biopsy samples were taken from the post-ESD scar or other suspicious mucosal abnormalities. H. pylori status was evaluated by performing rapid urease test and Wright-Giemsa staining of gastric biopsy samples at all follow-up examinations. Abdominal computed tomography was performed annually to assess distant metastasis.

\section{Statistical analysis}

Baseline data were obtained from our retrospectively collected medical records. Most variables, such as age and tumor size, were expressed as the mean \pm standard deviation. Chi-square test and Fisher's exact test were applied to compare metachronous recurrence. Student's t-test was used for performing intergroup comparisons of non-categorical clinical pathological variables. A univariate Cox proportional hazards model was used to identify possible covariates as significant risk factors for metachronous recurrence. Then, the variables with a $P$-value of $<0.05$ were subjected to multivariate Cox proportional hazards model to identify their independent contribution. Additionally, the variables considered to be possible risk factors for metachronous recurrence based on previous researches were also used in a multivariate model. All results were considered statistically significant at $P$-values of $<0.05$. Statistical analyses were performed using the Statistical Package for Social Science Version 18.0 (SPSS Inc., Chicago, IL, USA).

\section{RESULTS}

\section{Baseline characteristics}

A total of 180 patients who underwent ER of gastric neoplasm were enrolled. Baseline clinicopathologic characteristics of the patients were shown in Table 1 . The enrolled patients included 118 males and 62 females, and their median age was $61.7 \pm 10.3$ years. During the follow-up period (median: 34.5 years, range: 11 121 years), metachronous recurrence was observed in 21 patients (11.7\%). There were no statistically significant differences between patients without and with metachronous recurrence in terms of sex, smoking history, location, and gross appearance as well as the diameter, histology, or the depth of tumor. However, patients with metachronous recurrence had a significantly higher family history of gastric cancer $(P=0.041)$.

The mean age of 21 patients with metachronous recurrence was $62.3 \pm 14.6$ years, and $14(66.7 \%)$ of the patients were males. The average tumor size was $2.5 \mathrm{~cm}$ (range: 1.0 4.0 cm) in diameter. Of 21 lesions, one (4.8\%), 11 (52.4\%), and nine (42.8\%) lesions developed in the upper, middle, and lower third of the stomach, 
respectively. Sixteen patients (76.2\%) had a family history of gastric cancer. The median time to recurrence was 48.4 months (range: 6 121 months). Metachronous recurrence consisted of adenocarcinoma (14 patients, 8.8\%) and dysplasia (seven patients, 4.4\%), respectively. Except for the eight patients who were transferred to another hospital, all metachronous recurrence were treated by operation (four patients, 30.8\%) or ESD (nine patients, 69.2\%).

Table 1. Comparison of Clinicopathological Characteristics between Patients with and without Metachronous Recurrence

\begin{tabular}{|c|c|c|c|}
\hline Variable & $\begin{array}{l}\text { Patients without metachronous } \\
\text { recurrence }(n=159)\end{array}$ & $\begin{array}{l}\text { Patients with metachronous } \\
\text { recurrence }(\mathrm{n}=21)\end{array}$ & $P$-value \\
\hline Age (years) & & & 0.932 \\
\hline$<65$ & $96(60.3)$ & $12(57.1)$ & \\
\hline$\geq 65$ & $63(39.7)$ & 9 (42.9) & \\
\hline Sex & & & 0.897 \\
\hline Male & $104(65.4)$ & $14(66.7)$ & \\
\hline Female & $55(34.6)$ & $7(33.3)$ & \\
\hline Smoking & & & 0.358 \\
\hline Non-smoker & $108(67.9)$ & $19(90.5)$ & \\
\hline Ex-smoker & $18(11.3)$ & $2(9.5)$ & \\
\hline Current smoker & $33(20.8)$ & $0(0.0)$ & \\
\hline Location & & & 0.217 \\
\hline Upper & $4(2.5)$ & $1(4.8)$ & \\
\hline Middle or lower & $155(97.5)$ & $20(95.2)$ & \\
\hline Gross type & & & 0.750 \\
\hline Elevated & $81(50.9)$ & $9(42.9)$ & \\
\hline Flat & $59(37.1)$ & 9 (42.9) & \\
\hline Depressed & $19(12.0)$ & $3(14.2)$ & \\
\hline Histology & & & 0.304 \\
\hline Low grade dysplasia & $52(32.7)$ & $4(19.0)$ & \\
\hline Moderate grade dysplasia & $16(10.5)$ & $1(4.8)$ & \\
\hline High grade dysplasia & $25(15.7)$ & $5(23.8)$ & \\
\hline Adenocarcinoma & $65(41.1)$ & $11(52.4)$ & \\
\hline Depth of invasion & & & 0.512 \\
\hline Mucosa & $154(96.8)$ & $20(95.2)$ & \\
\hline Submucosa & $5(3.2)$ & $1(4.8)$ & \\
\hline Family history of gastric cancer & & & 0.041 \\
\hline Yes & $16(10.1)$ & $16(76.2)$ & \\
\hline No & $143(89.9)$ & $5(23.8)$ & \\
\hline Maximum diameter of lesion $(\mathrm{cm})$ & & & 0.937 \\
\hline$<2.5$ & $77(48.4)$ & $10(47.6)$ & \\
\hline$\geq 2.5$ & $82(51.6)$ & $11(52.4)$ & \\
\hline Helicobacter pylori status & & & 0.432 \\
\hline No infection & $83(60.1)$ & $12(57.1)$ & \\
\hline Eradicated & $38(27.5)$ & $8(38.1)$ & \\
\hline Not eradicated & $17(12.4)$ & $1(4.8)$ & \\
\hline \multicolumn{4}{|l|}{ Metachronous recurrence } \\
\hline \multicolumn{4}{|l|}{ Yes } \\
\hline Dysplasia & $7(4.4)$ & & \\
\hline Cancer & $14(8.8)$ & & \\
\hline No & $139(86.8)$ & & \\
\hline
\end{tabular}

Values are presented as number (\%). 


\section{Risk factors for metachronous recurrence}

According to univariate analysis, there were statistically significant differences in tumor location $(P=0.014)$ and family history of gastric cancer $(P=0.041)$ between patients with metachronous recurrence and those without metachronous recurrence. Family history of gastric cancer was the only independent risk factor for metachronous recurrence (OR=4.663, 95\% CI: 1.274 17.067, $P=0.020$ ) in multivariate analysis. However, H. pylori eradication was not associated with metachronous recurrence after ESD of gastric neoplasm was performed (Table 2). With regard to

Table 2. Analysis of the Risk of Metachronous Recurrence after Endoscopic Submucosal Dissection

\begin{tabular}{|c|c|c|c|c|c|}
\hline \multirow[b]{2}{*}{ Variable } & \multicolumn{3}{|c|}{ Univariate analysis } & \multicolumn{2}{|c|}{ Multivariate analysis } \\
\hline & $\begin{array}{l}\text { Patients without } \\
\text { metachronous recurrence } \\
\qquad(\mathrm{n}=159)\end{array}$ & $\begin{array}{l}\text { Patients with metachronous } \\
\text { recurrence }(n=21)\end{array}$ & $P$-value & HR $(95 \%$ CI $)$ & $P$-value \\
\hline Age (years) & & & 0.692 & $1.087(0.401 \sim 2.943)$ & 0.870 \\
\hline$<65$ & $96(60.3)$ & $12(57.1)$ & & & \\
\hline$\geq 65$ & $63(39.7)$ & $9(42.9)$ & & & \\
\hline Sex & & & 0.323 & $1.548(0.527 \sim 4.544)$ & 0.427 \\
\hline Male & $104(65.4)$ & $14(66.7)$ & & & \\
\hline Female & $55(34.6)$ & $7(33.3)$ & & & \\
\hline Helicobacter pylori status & & & 0.702 & $1.088(0.538 \sim 2.201)$ & 0.814 \\
\hline No infection & $83(60.1)$ & $12(57.1)$ & & & \\
\hline Eradicated & $38(27.5)$ & $8(38.1)$ & & & \\
\hline Not eradicated & $17(12.4)$ & $1(4.8)$ & & & \\
\hline Location & & & 0.014 & $1.054(0.542 \sim 3.271)$ & 0.310 \\
\hline Upper third & $4(2.5)$ & $1(4.8)$ & & & \\
\hline Middle or lower & $155(97.5)$ & $20(95.2)$ & & & \\
\hline Gross type & & & 0.658 & & \\
\hline Elevation & $81(50.9)$ & $9(42.9)$ & & & \\
\hline Flat & $59(37.1)$ & $9(42.9)$ & & & \\
\hline Depression & $19(12.0)$ & $3(14.2)$ & & & \\
\hline Histology grade & & & 0.681 & & \\
\hline Low grade dysplasia & $52(32.7)$ & $4(19.0)$ & & & \\
\hline Moderate grade dysplasia & $16(10.5)$ & $1(4.8)$ & & & \\
\hline High grade dysplasia & $25(15.7)$ & $5(23.8)$ & & & \\
\hline Adenocarcinoma & $65(41.1)$ & $11(52.4)$ & & & \\
\hline Family history of gastric cancer & & & 0.041 & $4.663(1.274 \sim 17.067)$ & 0.020 \\
\hline Yes & $16(10.1)$ & $16(76.2)$ & & & \\
\hline No & $143(89.9)$ & $5(23.8)$ & & & \\
\hline Maximum diameter of lesion $(\mathrm{cm})$ & & & 0.643 & $1.132(0.423 \sim 3.025)$ & 0.805 \\
\hline$<2.5$ & $77(48.4)$ & $10(47.6)$ & & & \\
\hline$\geq 2.5$ & $82(51.6)$ & $11(52.4)$ & & & \\
\hline Smoking & & & 0.751 & & \\
\hline Non-smoker & $108(67.9)$ & $19(90.5)$ & & & \\
\hline Ex-smoker & $18(11.3)$ & $2(9.5)$ & & & \\
\hline Current smoker & $4(2.5)$ & $0(11.5)$ & & & \\
\hline
\end{tabular}

Values are presented as number (\%).

$\mathrm{HR}$, hazard ratio; CI, confidence interval. 
the patients with metachronous recurrence, there were 12 patients in the H. pylori-negative group (12/95, 12.6\%), eight patients in the $H$. pylori-eradicated group (8/46, 17.4\%), and one patient in the $H$. pylori-persistent group (1/19, 5.2\%). The incidence of metachronous recurrence was higher in the H. pylori-eradicated group than that in the other groups without statistical sig- nificance $(P=0.432)$. The median interval between ESD and metachronous recurrence was 48.4 (range: 12 121) months (i.e., 46.7 months in the H. pylori-negative group, 54.1 months in the $H$. pylori-eradicated group, and 44.4 months in the H. pylori-persistent group). There were no significant differences in the baseline clinicopathologic characteristics of patients with metachronous recurrence

Table 3. Baseline Characteristics of Patients with Metachronous Recurrence According to Helicobacter pylori Infection Status

\begin{tabular}{|c|c|c|c|c|}
\hline & $\begin{array}{l}\text { H. pylori negative group } \\
\qquad(\mathrm{n}=95)\end{array}$ & $\begin{array}{l}\text { H. pylori eradicated group } \\
\qquad(\mathrm{n}=46)\end{array}$ & $\begin{array}{l}\text { H. pylori persistent group } \\
\qquad(\mathrm{n}=18)\end{array}$ & $P$-value \\
\hline Age (years) & & & & 0.098 \\
\hline$<65$ & $55(57.9)$ & $33(71.7)$ & $8(44.4)$ & \\
\hline$\geq 65$ & $40(42.1)$ & $13(28.3)$ & $10(55.6)$ & \\
\hline Sex & & & & 0.913 \\
\hline Male & $63(66.3)$ & $30(65.2)$ & $11(61.1)$ & \\
\hline Female & $32(33.7)$ & $16(34.8)$ & 7 (38.9) & \\
\hline Smoking & & & & 0.320 \\
\hline Non-smoker & $68(71.6)$ & $29(63.0)$ & $11(61.1)$ & \\
\hline Ex-smoker & $7(7.4)$ & $7(15.2)$ & $4(22.2)$ & \\
\hline Current smoker & $20(21.1)$ & $10(21.7)$ & $3(16.7)$ & \\
\hline Location & & & & 0.772 \\
\hline Upper & $2(2.1)$ & $1(2.2)$ & $1(5.6)$ & \\
\hline Middle or lower & $93(97.9)$ & $45(97.8)$ & $17(94.4)$ & \\
\hline Gross type & & & & 0.990 \\
\hline Elevated & $48(50.5)$ & $23(50.0)$ & $10(55.6)$ & \\
\hline Flat & $35(36.8)$ & $18(39.1)$ & $6(11.1)$ & \\
\hline Depressed & $12(12.6)$ & $5(10.9)$ & $2(11.1)$ & \\
\hline Histology & & & & 0.396 \\
\hline Low grade dysplasia & $33(34.7)$ & $15(33.3)$ & $4(22.2)$ & \\
\hline Moderate grade dysplasia & $9(9.5)$ & $7(15.6)$ & $0(0.0)$ & \\
\hline High grade dysplasia & $13(13.7)$ & $7(15.6)$ & $5(27.8)$ & \\
\hline Adenocarcinoma & $40(42.1)$ & $16(35.6)$ & $9(50.0)$ & \\
\hline Family history of gastric cancer & & & & 0.289 \\
\hline Yes & $12(12.6)$ & $2(4.3)$ & $2(11.1)$ & \\
\hline No & $83(87.4)$ & $44(95.7)$ & $16(88.9)$ & \\
\hline Maximum diameter of lesion $(\mathrm{cm})$ & & & & 0.972 \\
\hline$<2.5$ & $45(47.4)$ & $23(50.0)$ & $9(50.0)$ & \\
\hline$\geq 2.5$ & $50(52.6)$ & $23(50.0)$ & $9(50.0)$ & \\
\hline Metachronous recurrence & & & & 0.432 \\
\hline \multicolumn{5}{|l|}{ Yes } \\
\hline Dysplasia & $4(33.3)$ & $3(37.5)$ & $0(0.0)$ & \\
\hline Cancer & $8(66.7)$ & $5(62.5)$ & $1(100.0)$ & \\
\hline No & $83(87.4)$ & $38(82.6)$ & $18(94.4)$ & \\
\hline
\end{tabular}

Values are presented as number (\%).

H. pylori, Helicobacter pylori. 
among the groups (Table 3).

\section{DISCUSSION}

ESD has now been widely accepted as a useful, standard treatment for certain EGCs worldwide. ESD offers minimally invasive treatment at a lower cost, but metachronous recurrence after ESD is still a matter of concern. Risk factors for metachronous recurrence after ER of gastric neoplasm were male sex, older age, multiple initial EGCs, family history of gastric cancer, and persistent $H$. pylori infection. ${ }^{15,16}$ The present study shows that the family history of gastric cancer could play an important role in metachronous recurrence after ESD is performed for gastric neoplasm. However, $H$. pylori eradication after ESD did not significantly reduce the incidence of metachronous recurrence.

Our analysis reported a metachronous recurrence rate of $11.7 \%$ after ESD for gastric neoplasm is performed. Other studies have shown an incidence rate of metachronous recurrence ranging from $2.7 \%$ to $15.6 \% .{ }^{17-20}$ Taking the short follow-up period into account, the prevalence of metachronous recurrence in the present study is comparatively higher. With regard to metachronous recurrence, a large-population retrospective study reported that the 5-year, 7-year, and 10-year cumulative incidence rates of metachronous recurrence were 9.5\%, 13.1\%, and $22.7 \%$, retrospectively. ${ }^{18}$ A previous study reported that the risk of metachronous recurrence increased at a proportion of >5-year follow-up duration, regardless of the presence of $H$. pylori. ${ }^{21}$ Continuous endoscopic surveillance after ESD is important to prevent metachronous recurrence.

After making adjustments during statistical analysis, a family history of gastric cancer was found to be an independent risk factor for metachronous recurrence. In this study, a history of gastric cancer in first-degree relatives increased the risk of metachronous recurrence by approximately four-fold. Although most gastric neoplasms are sporadic, approximately 10\% show familial aggregation. ${ }^{22}$ The risk of gastric neoplasm in patients with a family history is higher than the risk associated with other solid cancers. ${ }^{23}$ First, family members share some common etio- logical factors such as exposure to carcinogens, dietary habits, and virulence of bacteria including H. pylori as well as common genetic backgrounds, ${ }^{24}$ and second, family history of gastric neoplasm increases the susceptibility to gastric carcinogenesis. ${ }^{25-28}$

Family history of gastric cancer has been known as a risk factor of gastric neoplasm. ${ }^{29}$ Our findings revealed that patients with metachronous recurrence are more likely to have a family history of gastric cancer. Similarly, a study by Kim et al. ${ }^{30}$ reported that family history of gastric cancer (hazard ratio 2.60, $P=0.014$ ) was related to metachronous gastric neoplasm development. Although EGC has increased the number of patients undergoing $\mathrm{ESD}$, there is no established guideline for effective follow-up after ESD. If the risk of metachronous recurrence of gastric cancer is high in patients who undergo ESD, it is preferable to subject them to a more intensive follow-up than that done for the general population without any risk factors for recurrence. Our results indicated that patients with a family history of gastric cancer have a high risk of metachronous recurrence. This group will benefit from a more frequent endoscopic follow-up schedule after ESD treatment.

H. pylori infection is considered to be one of the most important risk factors for gastric neoplasm. However, it remains controversial whether $H$. pylori eradication actually suppresses metachronous recurrence after ESD. Our study shows that $H$. pylori eradication after ESD of gastric neoplasm did not significantly reduce the incidence of metachronous recurrence. In a recent randomized controlled trial, H. pylori eradication did not produce significant changes in molecular alterations related to carcinogenesis, suggesting that $H$. pylori treatment may not prevent metachronous recurrence in the background mucosa with intestinal metaplasia. ${ }^{31}$ The molecular changes associated with carcinogenesis have not been improved by $H$. pylori eradication, which means that the eradication does not prevent metachronous recurrence after ESD. As opposed to our study, several retrospective studies have considered persistent $H$. pylori as a risk factor for metachronous recurrence after ESD. ${ }^{32-34} H$. pylori eradication causes the disappearance of neutrophilic infiltration in the gastric mucosa, which in turn results in 
the reduction of lymphocyte and plasma cell infiltration in the gastric mucosa. ${ }^{35}$ H. pylori eradication exerts a preventive effect on intestinal metaplasia and gastric atrophy; ${ }^{36}$ consequently, the occurrence of metachronous recurrence in patients who receive endoscopic treatment can be reduced. A recent double-blind, randomized trial ${ }^{37}$ was designed to evaluate whether $H$. pylori treatment prevents metachronous recurrence and decreases histologic changes in patients with EGC; in that study, it was revealed that as opposed to patients who received placebo, $H$. pylori treatment resulted in lower incidence rates of metachronous recurrence and more improvement from baseline in gastric atrophy grade. However, H. pylori treatment did not affect the subsequent incidence of adenoma or overall survival.

Several limitations of this study warrant discussion. First, it was performed at a single center and had a retrospective design. This could induce selection bias with regard to the generalization of results. The number of subjects in the H. pylori-persistent group was substantially smaller than that in the $H$. pylori-eradicated group. Second, the number of patients is small and the follow-up period is short for confirming the effect of $H$. $p y^{-}$ lori eradication on metachronous recurrence. Finally, atrophy and intestinal metaplasia in the background mucosa were not histologically evaluated. The serum pepsinogen I/II ratio or the degree of gastric mucosal atrophy during histological evaluation had to be confirmed.

In conclusion, H. pylori eradication was not found to be associated with metachronous recurrence after ESD of gastric neoplasm. However, the development of metachronous recurrence might be affected by family history of gastric cancer. Therefore, intensive surveillance is required for patients having a family history of gastric cancer and who undergo ESD of gastric neoplasm.

\section{CONFLICT OF INTEREST}

No potential conflict of interest relevant to this article was reported.

\section{ORCID}

A Reum Choe (D) https://orcid.org/0000-0002-2552-7066

\begin{abstract}
Ki-Nam Shim
(D) https://orcid.org/0000-0003-4004-6292

Tae Oh Kim

(iD https://orcid.org/0000-0002-6369-5618

Sang Yoon Kim

(D) https://orcid.org/0000-0002-1155-1495

Jiyoung Lim

(D) https://orcid.org/0000-0002-3252-9035

Chung Hyun Tae

Chang Mo Moon

Seong-Eun Kim

(iD) https://orcid.org/0000-0002-0764-7793

Hye-Kyung Jung

(1D https://orcid.org/0000-0003-2550-913X

Sung-Ae Jung

(D) https://orcid.org/0000-0002-6310-5366

(D) https://orcid.org/0000-0002-6653-5214

(D) https://orcid.org/0000-0001-7224-2867
\end{abstract}

\section{REFERENCES}

1. Jung KW, Won YJ, Oh CM, Kong HJ, Lee DH, Lee KH. Prediction of cancer incidence and mortality in Korea, 2017. Cancer Res Treat 2017;49:306-312.

2. Sumiyama K. Past and current trends in endoscopic diagnosis for early stage gastric cancer in Japan. Gastric Cancer 2017;20 (Suppl 1):20-27.

3. Jun JK, Choi KS, Lee HY, et al. Effectiveness of the Korean national cancer screening program in reducing gastric cancer mortality. Gastroenterology 2017;152:1319-1328.e7.

4. Alfaro EE, Lauwers GY. Early gastric neoplasia: diagnosis and implications. Adv Anat Pathol 2011;18:268-280.

5. Fujishiro M, Yoshida S, Matsuda R, Narita A, Yamashita H, Seto Y. Updated evidence on endoscopic resection of early gastric cancer from Japan. Gastric Cancer 2017;20(Suppl 1):39-44.

6. Emura F, Mejía J, Donneys A, et al. Therapeutic outcomes of endoscopic submucosal dissection of differentiated early gastric cancer in a Western endoscopy setting (with video). Gastrointest Endosc 2015;82:804-811.

7. Sun K, Chen S, Ye J, et al. Endoscopic resection versus surgery for early gastric cancer: a systematic review and meta-analysis. Dig Endosc 2016;28:513-525.

8. Bhatt A, Abe S, Kumaravel A, Vargo J, Saito Y. Indications and techniques for endoscopic submucosal dissection. Am J Gastroenterol 2015;110:784-791.

9. Chang JY, Shim KN, Tae CH, et al. Comparison of clinical outcomes after endoscopic submucosal dissection and surgery in the treatment of early gastric cancer: a single-institute study. Medicine (Baltimore) 2017;96:e7210.

10. Shin DW, Hwang HY, Jeon SW. Comparison of endoscopic submucosal dissection and surgery for differentiated type early gastric cancer within the expanded criteria. Clin Endosc 2017;50:170-178.

11. Meng FS, Zhang ZH, Wang YM, Lu L, Zhu JZ, Ji F. Comparison of endoscopic resection and gastrectomy for the treatment of early gastric cancer: a meta-analysis. Surg Endosc 2016;30: 3673-3683.

12. Libânio D, Pimentel-Nunes P, Afonso LP, Henrique R, Dinis-Ribeiro M. Long-term outcomes of gastric endoscopic submucosal dissection: focus on metachronous and non-cura- 
tive resection management. GE Port J Gastroenterol 2017; 24:31-39.

13. Hu J, Zhao Y, Ren M, et al. The comparison between endoscopic submucosal dissection and surgery in gastric cancer: a systematic review and meta-analysis. Gastroenterol Res Pract 2018; 2018:4378945.

14. Han SJ, Kim SG, Lim JH, et al. Long-term effects of Helicobacter pylori eradication on metachronous gastric cancer development. Gut Liver 2018;12:133-141.

15. Park WY, Lee SJ, Kim YK, et al. Occurrence of metachronous or synchronous lesions after endoscopic treatment of gastric epithelia dysplasia- impact of histologic features of background mucosa. Pathol Res Pract 2018;214:95-99.

16. Warren S. Multiple primary malignant tumors. A survey of the literature and a statistical study. Am J Cancer 1932;16:1358-1414.

17. Kim JJ, Lee JH, Jung HY, et al. EMR for early gastric cancer in Korea: a multicenter retrospective study. Gastrointest Endosc 2007;66:693-700.

18. Abe S, Oda I, Suzuki H, et al. Long-term surveillance and treatment outcomes of metachronous gastric cancer occurring after curative endoscopic submucosal dissection. Endoscopy 2015; 47:1113-1118.

19. Hahn KY, Park JC, Kim EH, et al. Incidence and impact of scheduled endoscopic surveillance on recurrence after curative endoscopic resection for early gastric cancer. Gastrointest Endosc 2016;84:628-638.e1.

20. Lee HJ, Lee YJ, Lee JY, et al. Characteristics of synchronous and metachronous multiple gastric tumors after endoscopic submucosal dissection of early gastric neoplasm. Clin Endosc 2018;51:266-273.

21. Maehata Y, Nakamura S, Fujisawa K, et al. Long-term effect of Helicobacter pylori eradication on the development of metachronous gastric cancer after endoscopic resection of early gastric cancer. Gastrointest Endosc 2012;75:39-46.

22. Oliveira C, Seruca R, Carneiro F. Hereditary gastric cancer. Best Pract Res Clin Gastroenterol 2009;23:147-157.

23. Yaghoobi M, Bijarchi R, Narod SA. Family history and the risk of gastric cancer. Br J Cancer 2010;102:237-242.

24. Rugge M, Fassan M, Graham DY. Epidemiology of gastric cancer. In: Strong VE. Gastric cancer. New York: Springer, 2015;23-34.

25. Lee IS, Park YS, Kim KC, et al. Multiple synchronous early gastric cancers: high-risk group and proper management. Surg Oncol 2012;21:269-273.

26. Shin CM, Kim N, Yang HJ, et al. Stomach cancer risk in gastric cancer relatives: interaction between Helicobacter pylori in- fection and family history of gastric cancer for the risk of stomach cancer. J Clin Gastroenterol 2010;44:e34-e39.

27. Brenner H, Arndt V, Stürmer T, Stegmaier C, Ziegler H, Dhom G. Individual and joint contribution of family history and Helicobacter pylori infection to the risk of gastric carcinoma. Cancer 2000;88:274-279.

28. Yoon H, Kim N, Shin CM, et al. Risk factors for metachronous gastric neoplasms in patients who underwent endoscopic resection of a gastric neoplasm. Gut Liver 2016;10:228-236.

29. Song H, Ekheden IG, Ploner A, Ericsson J, Nyren O, Ye W. Family history of gastric mucosal abnormality and the risk of gastric cancer: a population-based observational study. Int J Epidemiol 2018;47:440-449.

30. Kim YI, Choi IJ, Kook MC, et al. The association between Helicobacter pyloristatus and incidence of metachronous gastric cancer after endoscopic resection of early gastric cancer. Helicobacter 2014;19:194-201.

31. Kawanaka M, Watari J, Kamiya N, et al. Effects of Helicobacter pylorieradication on the development of metachronous gastric cancer after endoscopic treatment: analysis of molecular alterations by a randomised controlled trial. Br J Cancer 2016; 114:21-29.

32. Kwon YH, Heo J, Lee HS, Cho CM, Jeon SW. Failure of Helicobacter pylori eradication and age are independent risk factors for recurrent neoplasia after endoscopic resection of early gastric cancer in 283 patients. Aliment Pharmacol Ther 2014;39:609-618.

33. Bae SE, Jung HY, Kang J, et al. Effect of Helicobacter pylorieradication on metachronous recurrence after endoscopic resection of gastric neoplasm. Am J Gastroenterol 2014;109: 60-67.

34. Chung, CS, Woo HS, Chung JW, et al. Risk factors for metachronous recurrence after endoscopic submucosal dissection of early gastric cancer. J Korean Med Sci 2017;32:421-426.

35. Kong YJ, Yi HG, Dai JC, Wei MX. Histological changes of gastric mucosa after Helicobacter pylori eradication: a systematic review and meta-analysis. World J Gastroenterol 2014;20: 5903-5911.

36. Ohkusa T, Fujiki K, Takashimizu I, et al. Improvement in atrophic gastritis and intestinal metaplasia in patients in whom Helicobacter pylori was eradicated. Ann Intern Med 2001; 134:380-386.

37. Choi IJ, Kook MC, Kim YI, et al. Helicobacter pylori therapy for the prevention of metachronous gastric cancer. N Engl J Med 2018;378:1085-1095. 